\title{
Pyrolysis of Printed Circuit Boards
}

\author{
T. R. Mankhand ${ }^{*}$ K. K. Singh, Sumit Kumar Gupta, Somnath Das
}

Department of Metallurgical Engineering, Indian Institute of Technology (Banaras Hindu University), Varanasi, 221005, India

\begin{abstract}
Printed Circuit Board (PCB) is an essential co mponent of almost all electrical and electron ic equip ments. The rapid growth of the use of such equipments has contributed enormously to the generation of large quantity of waste PCBs. The WPCBs not only contain valuable metals but also a large variety of hazardous materials. Conventional treatments of such WPCBs have their own limitations. By pyrolys is of WPCBs, it is not only possible to obtain the organic part of it as a fuel or useful chemical but can make further processing to recover metals much easier and efficient. In the present work, a kinetic study on the low temperature pyrolysis of WPCBs using a thermogravimetric analyser has been attempted. The TG analysis was conducted in nitrogen and air atmospheres in the temperature range of $200-600^{\circ} \mathrm{C}$ at a heating rate of $40^{\circ} \mathrm{C}$ $/ \mathrm{min}$. The kinetic expressions for both the environments were determined and the activation energies were found to be 110.7 and $90.2 \mathrm{~kJ} / \mathrm{mol}$ for nitrogen and air, respectively. The effect of thermal pre-treatment on the subsequent copper leaching in nitric acid for untreated, pyrolysed and air-burned PCB was also studied. Copper recoveries from these samples were $30.4 \%, 92.5 \%$ and $96.2 \%$, respectively indicating the importance of thermal pre-treatment in leaching of the metal content.
\end{abstract}

Keywords Pyrolysis, Printed Circuit Board (PCB), E-Waste, Copper Leaching

\section{Introduction}

Printed Circu it Board (PCB) is an essential component of almost all electronic and electrical equipments such as computers, televisions, mobile phones, entertainment devices, household appliances and other such items. The rapid growth of the use of such equipments, combined with their early obsolescence has contributed enormously to the generation of large quantity of electronic waste (e-waste). The UNEP estimates that the world is generating collectively about 20-50 million tons of e-waste every year.It is also predicted that by the year 2020, e-waste in India from old computers will jump 5 times, while from discarded mobile phones will be 18 times higher compared to 2007 level.

The printed circuit board is a major constituent of the obsolete and discarded electronic scrap and it accounts for approximately $30 \%$ of the total e-scrap generated. It has homogenous mixture of organic material, metals and glass fiber. The non-metals such as epoxy, glass fibre and other additives constitute about $70 \%$ by weight of PCBs while remaining $30 \%$ constitute metals such as copper, tin, lead, iron and nickel. In the metal fraction the approximate contents are: copper- $17 \%$, solder $-4 \%$, iron- $3 \%$ and nickel-2\%. Precious metals such as gold, silver and palladium are also present in small quantities[1-2]. PCBs

* Corresponding author:

trmankhand@yahoo.co.in (T. R. Mankhand)

Published online at http://journal.sapub.org/ijmee

Copyright (C) 2012 Scientific \& Academic Publishing. All Rights Reserved also contain a variety of heavy metals and hazardous substances viz., lead, cadmium, mercury, PVC and halogenated flame retardants etc. that may seriously pollute the environment if they are not properly disposed of. Moreover, the recycling of WPCBs is difficult due to their multi-component and multi-layered construction. Therefore, developing a non-polluting and economical processing technology for recycling of WPCBs is needed not only to recycle valuable resources but also to avoid environmental pollution.

Traditionally, pyrometallurgical[3], hydrometallurgical [4-6] and mechanical processing[7-9] have been used to recycle WPCBs. Pyrometallurgical processes involve combustion, smelting in molten bath etc. In this process crushed scrap is charged in a molten bath to remove plastics and refractory oxides to form a slag containing valuable metals. However, it leads to formation of hazardous by-product fumes and only a partial recovery of metals could be achieved. Compared to pyrometallurgy, hydrometallu rgi cal methods are more exact, highly predictable and easily controlled but many of the solvents used like cyanides and chlorides are highly hazardous. It also involves large number of steps, has high cost of recovery and generates waste solutions and sludge which create environmental pollution. Mechanical processingincludes multi-crushing, grinding, gravity, electrostatic, magnetic and density based separation methods. However, such methods produce much dust and harmful particulate matter. Moreover, the non-metallic powder obtained can only be used as low-value products, viz. paint, paving material, plastic filling material etc., while the 
precious metals may be lost as they usuallyadhere to the non-metallic powder in crushing and grinding.

Pyrolysis is a thermochemical decomposition of organic material at elevated temperatures (generally without the participation of oxygen). It involves the simultaneous change of chemical composition and physical phase, and is irreversible. It can be considered as an alternative method for recycling $\mathrm{PCB}$, because in the pyrolysis process, the organic part is decomposed to low molecular products (liquids or gases), which can be used as fuel or chemical source, furthermore PCB changes brittle, undergoes delamination which could be easily crushed, while the inorganic part such as glass-fibre remain fairly intense, which can be recycled into other composites or any other materials [10-11].

Pyrolysis is a thermal recycling technique that has been widely researched as a method of recycling synthetic polymers including polymers that are mixed with glass fibres. Although a significant amount of research into the pyrolysis of PCBs has been reported, most of the work has been carried out under nitrogen atmosphere using analytical pyrolysis techniques or laboratory scale reactors involving measurement of kinetics[12-15] and characterization of its products obtained[16-18].

In this present study a kinetic analysis of the low temperature pyrolysis of WPCBs has been studied under nitrogen and air atmosphere. The effect of thermal pre-treatment on the leaching of copper from untreated, pyrolysed and air-burned (combustion) samples was also examined.

\section{Experimental}

\subsection{Materials}

Printed Circuit Boards (PCBs), (a part of computer mother board) were collected from old and obsolete computers through local sources (Figure.1 (a)). The batteries, capacitors and other electronic devises fro $\mathrm{m}$ PCBs were mechanically removed in order to get clean and component free PCBs. A number of such boards were crushed using laboratory jaw crusher to get pieces in the size range of $3-5 \mathrm{~cm}$. These large pieces were further reduced to size of 3-5 mm (Figure.1 (b)) using a manual cutter.

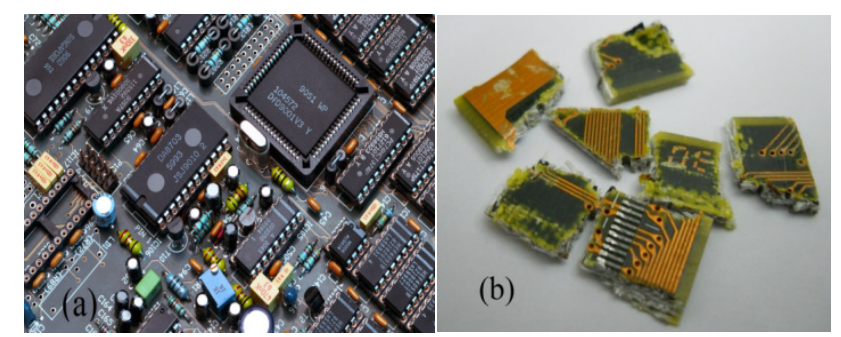

Figure 1. (a)PCB from computer mother board (b) after cutt ing

\subsection{Apparatus and Methods}

\subsubsection{Pyrolysis}

The PCB particles of the size in the range of $3-5 \mathrm{~mm}$ were subjected to pyrolysis under nitrogen atmosphere using a thermogravimetricanalyser. It measures continually the change in weight of the samples undergoing reactions at the specified temperatures with the help of a cathetometer. A schematic diagram of the apparatus is shown Figure. 2.

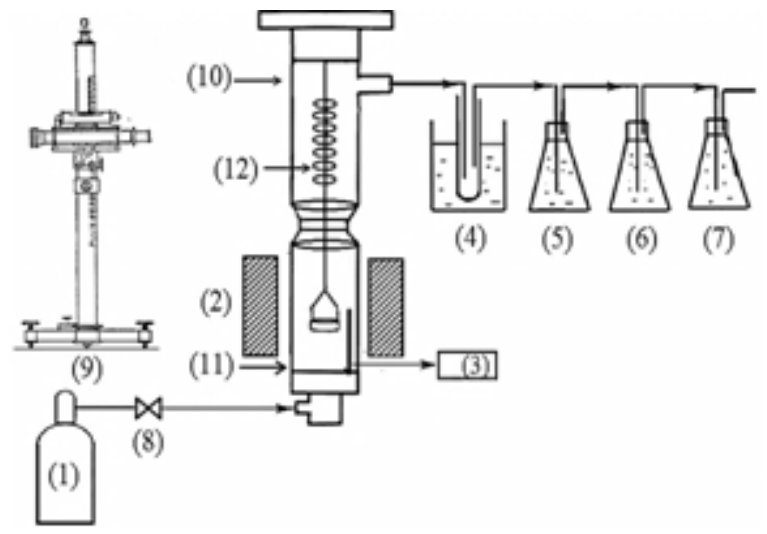

Figure 2. Schematic diagram of the thermogravimetric apparatus.(1) Nitrogen Cylinder (2) Furnace (3) Temperature Controller (4) Condenser (5) Distilled Water (6) $\mathrm{H}_{2} \mathrm{SO}_{4}$ Solution (7) $\mathrm{NaOH}$ Solution (8)Valve (9) Cathetometer (10) Pyrex Tube (11) Silica Tube (12) Calibrated Spring

It consisted of a spring assembly, fixed to a vertically mounted transparent silica tube, which itself was placed in a vertically movable resistance furnace. From the prior calibrated spring fixed in the upper part of the assembly, a silica crucible containing the sample was suspended in the silica tube. The furnace was aligned to bring the sample crucible in the middle of the furnace. The temperature of the furnace was measured by inserting a thermocouple from the bottom of the silica tube. During pyrolysis of the PCB samples, the weight loss was continually monitored with the help of a cathetometer. The weight loss was converted to fraction reacted $(\alpha)$ by the equation:

$$
\alpha=\frac{W_{i}-W_{t}}{W_{i}-W_{f}}
$$

Where $W_{i}, W_{t}$ and $W_{f}$, represents initial, at time $\mathrm{t}$ and final we ight loss of the sample, respectively. The pyrolysis experiments were carried out in the temperature range of $200-600^{\circ} \mathrm{C}$ at an interval of $100^{\circ} \mathrm{C}$ and at a heating rate of $40^{\circ} \mathrm{C} / \mathrm{min}$, in each case until the set temperature was obtained. Upon reaching the requisite temperature it was maintained constant throughout the entire process. When the experiments were finished, the furnace power was turned off but the carrier gas was kept flowing until the reactor was cooled down to the room temperature. High purity nitrogen was used as a purge gas and the exiting products of pyrolysis were trapped in the condenser system as shown in Figure 2. It consisted of a water cooled empty condenser, distilled water to trap the water soluble products and the remaining two containing $1 \mathrm{M} \mathrm{H}_{2} \mathrm{SO}_{4}$ and $1 \mathrm{M} \mathrm{NaOH}$ solutions to take care of other products of pyrolysis.

In order to observe the effect of environment on pyrolysis behaviour separate experiments were conducted in air under similar conditions. However no condensation system was employed during these experiments. 


\subsubsection{Leach ing}

Leaching of the pyrolysed samples were carried out to assess the recovery of copper. It was done in $1 \mathrm{M}$ solution of $\mathrm{HNO}_{3}$ at $80^{\circ} \mathrm{C}$ for 60 minutes using constant stirring in a glass reactor. In order to compare the leaching behaviour, the samples without thermal treatment, the ones burned in air and the ones pyrolysed in nitrogen were leached under similar conditions. The leaching experiments were carried out in a Pyrex beaker provided with a heater to maintain the requisite temperature. The pulp densities used in all the cases were $25 \mathrm{~g} / \mathrm{L}$. All the samples had retained their shape and size. A stirring speed of $300 \mathrm{rpm}$ was maintained to avoid splashing of acid. During experiments, the liquid samples were withdrawn at regular time intervals and analysed for their copper content using a spectrophotometer.

\section{Results and Discussion}

\subsection{Ther mogravimetric Results}

\subsubsection{In Nitrogen}

To evaluate the rate of pyrolysis of PCB particles, thermogravimetric studies were conducted at various temperatures viz. $300,400,500,600{ }^{\circ} \mathrm{C}$ at a constant heating rate of $40^{\circ} \mathrm{C} / \mathrm{min}$. under nitrogen atmosphere. The results are shown in Figure. 3. The percentage weight loss of the samples was calculated at various time intervals at different temperatures of study.

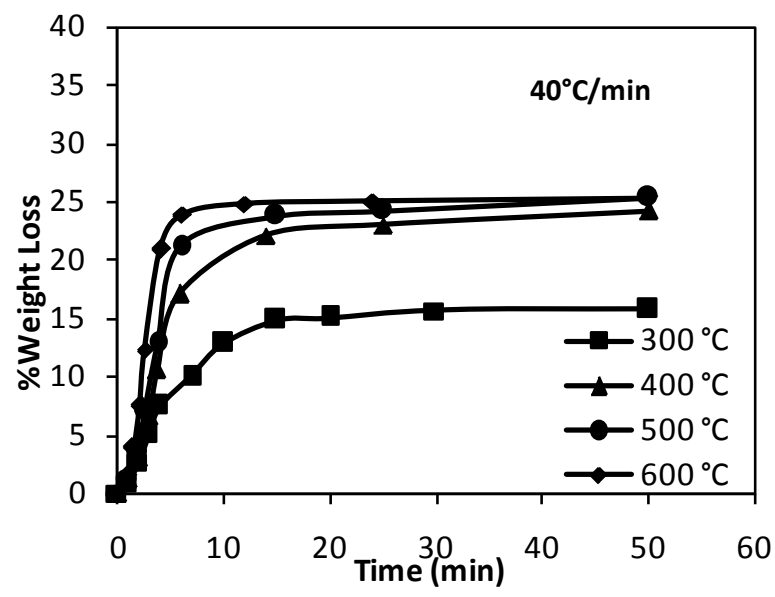

Figure 3. T Gcurves of pyrolysis of PCBs in nitrogen atmosphere

It was observed that weight loss increases with time at each temperature, initially rapidly and then becomes constant after about 15 minutes. Moreover the maximum weight loss increases with increasing up to the maximum temperatures of study which was observed as $25 \%$ at $600^{\circ} \mathrm{C}$ at about 50 minutes of pyrolysis.

In order to compare the weight loss of the samples at different temperatures at a particular time, the above results are replotted as shown in Figure. 4. The results are shown for the weight loss of the samples after $5,10,30,50$ minutes of pyrolysis. The figure depictsthat the process is very fast and the duration of thermal treatment at higher temperatures has not much influence on the amount of substance removed from the sample.

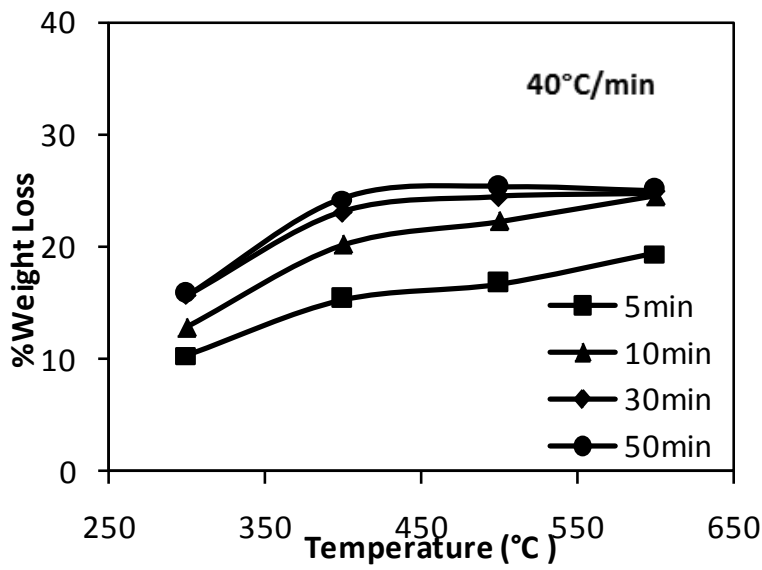

Figure 4. Temperature dependence of weight loss under nitrogen atmosphere

The figure also shows that the loss in weight of the PCB samples under nitrogen atmosphere at a constant temperature increases with time and then becomes constant. The total loss in weight at $600^{\circ} \mathrm{C}$ for 10,30 and 50 minutes was virtually the same i.e. about $25 \%$. However at $300^{\circ} \mathrm{C}$ the maximum weight loss even after 50 minutes was only $16 \%$, this is because most of plastics are thermally degradable only above this temperature. It can be concluded from the above that temperature of $500^{\circ} \mathrm{C}$ andduration of 50 minutes are sufficient for the effective removal of volatile co mpounds of the PCBs.

\subsubsection{In Air}

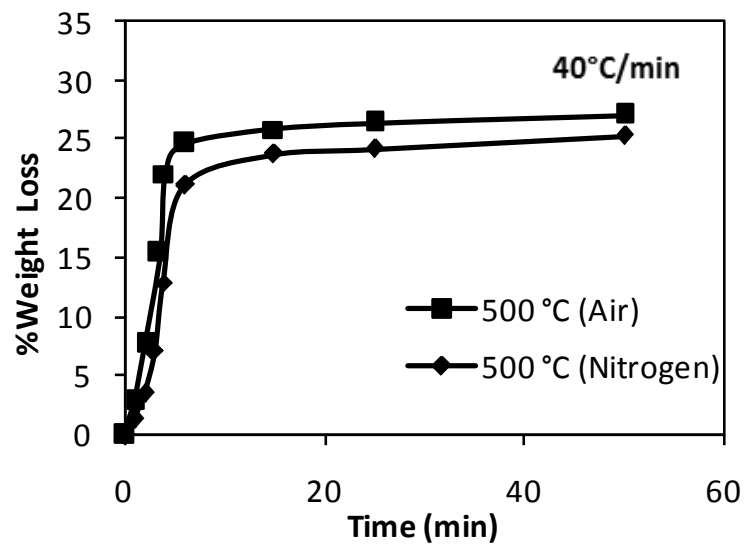

Figure 5. Comparison of pyrolysis performances of $\mathrm{PCBs}$ under nitrogen and air

To compare the combustion behaviour of PCBs in air, similar thermogravimetric experiments were performed as that in nitrogen atmosphere.

Figure. 5 shows a comparison of pyrolysis of PCB samples under nitrogen and air at $500^{\circ} \mathrm{C}$ for the same duration of time $\left(50\right.$ minutes) and heating rate $\left(40^{\circ} \mathrm{C} / \mathrm{min}\right)$. A little higher $(27 \%)$ weight loss was observed by burning the sample in air as compared $25 \%$ obtained for pyrolys is in nitrogen. 
During heating in air, combustion of plastics occurs and the gaseous products which are formed are released easier than volatile compounds released in nitrogen atmosphere. Also rate of removal of mass was observed to be slightly faster in case of air than in nitrogen.

\subsection{Decomposition Behaviour}

Figure. 6 represents the decomposition behaviour of $\mathrm{PCB}$ scrap studied in the temperature range of $200-600^{\circ} \mathrm{C}$ using a thermogravimetric analyser at heating rates of $40^{\circ} \mathrm{C} / \mathrm{min}$. Based on this graph the decomposition behaviour of PCB scrap can be divided into three stages. The first stage was observed up to the temperature of $296^{\circ} \mathrm{C}$, where no weight loss of the PCB particles was observed. The next stage corresponds to the temperature range of $296^{\circ} \mathrm{C}$ to $500^{\circ} \mathrm{C}$ where the major weight loss of the PCB scrap took place. The third stage can be seen above $500^{\circ} \mathrm{C}$ where the rate of decomposition of the PCB scrap decreased, and became almost constant. This is because a large amount of the organic material had already been decomposed into gas and liquid products. The total mass loss of the sample accounted for about 24 wt. \%. Derivative TG (DTG) curve was also plotted to identify the temperature where weight loss is most apparent.

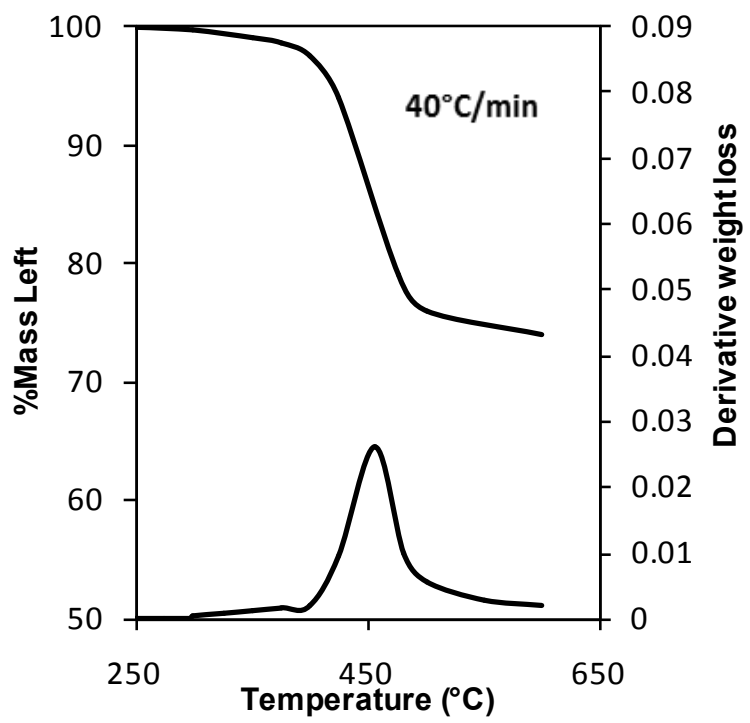

Figure 6. TG and DTG curves depicting stages of pyrolysis under nitrogen atmosphere

It can beobserved from the figure that the maximum pyrolysis (decomposition) was found in the temperature range of $400-500^{\circ} \mathrm{C}$. This was followed by a small wide band where minor loss of weight took place.

\subsection{Pyrolysis Kinetics}

It is possible to describe the pyrolysis behaviour of PCB scraps under different conditions by different pyrolysis mechanis ms[13],[19-22]. The decomposition rate of the pyrolysis process depends on an arbitrary reaction order. The reaction scheme can be represented as:

$$
\text { Raw Material } \stackrel{k}{\rightarrow} \text { Char + Volatiles }
$$

Where $k$ is the rate constant of the reaction following the Arrhenius law. It was assumed that the total reaction accords with the following conventional equation:

$$
A(\text { Solid }) \rightarrow B(\text { Solid })+C(\text { Volatile })
$$

According to the mass conservation law, the conversion rate was described as follows:

$$
\frac{d(1-\alpha)}{d t}=k(1-\alpha)^{n}
$$

Where $\alpha$ represents the weight loss ratio

$$
\alpha=\frac{W_{i}-W_{t}}{W_{i}-W_{f}} \text { (1) }
$$

andn, present in equation (3) was designated as the order of magnitude of the reaction. Generally, $n$ calculated in most of the solid compound pyrolysis reactions equals to1. From the derived kinetics expression in Arrhenius equation:

$$
K=A \exp \left(\frac{-E}{R T}\right)
$$

Hence, equation (3) could be represented as:

$$
\frac{d(1-\alpha)}{d t}=\operatorname{Aexp}\left(\frac{-E}{R T}\right)(1-\alpha)^{n}
$$

Equation (5) could be changed to

$$
\ln \ln \left(\frac{1}{1-\alpha}\right)=-\frac{E}{R T}+\text { const }
$$

The terms used in the above equations are as follows: $\mathrm{E}=$ Apparent activation energy $(\mathrm{kJ} / \mathrm{mol}), \quad \mathrm{T}=$ Absolute temperature $(\mathrm{K}), \mathrm{R}=$ Gas constant, $\mathrm{t}=$ Duration of pyrolysis, $\mathrm{A}=$ Frequency factor, $\mathrm{n}=$ Apparent reaction order, $W_{i}, W_{t}$ and $W_{f}$, represents initial, at time $\mathrm{t}$ and final weight loss of the sample, respectively.

Based on the information from the TG analysis and the above equations theln $\ln \left(\frac{1}{1-\alpha}\right)$ value along with $\left(\frac{1}{\mathrm{~T}}\right)$ under air and nitrogen atmospheres were calculated respectively, and are plotted, as shown in Figure. 7(a) and (b), respectively.

The apparent activation energies were found to be 90.26 and $110.7 \mathrm{~kJ} / \mathrm{mol}$ for the atmospheres of air and nitrogen surroundings, respectively.

The corresponding kinetic equations for these atmospheres are:

$$
\begin{gathered}
\mathrm{k}=15.756 \exp \left(-\frac{90.26 \times 10^{3}}{R T}\right)(\text { Air }) \\
k=18.451 \exp \left(-\frac{110.7 \times 10^{3}}{R T}\right)(\text { Nitrogen })
\end{gathered}
$$



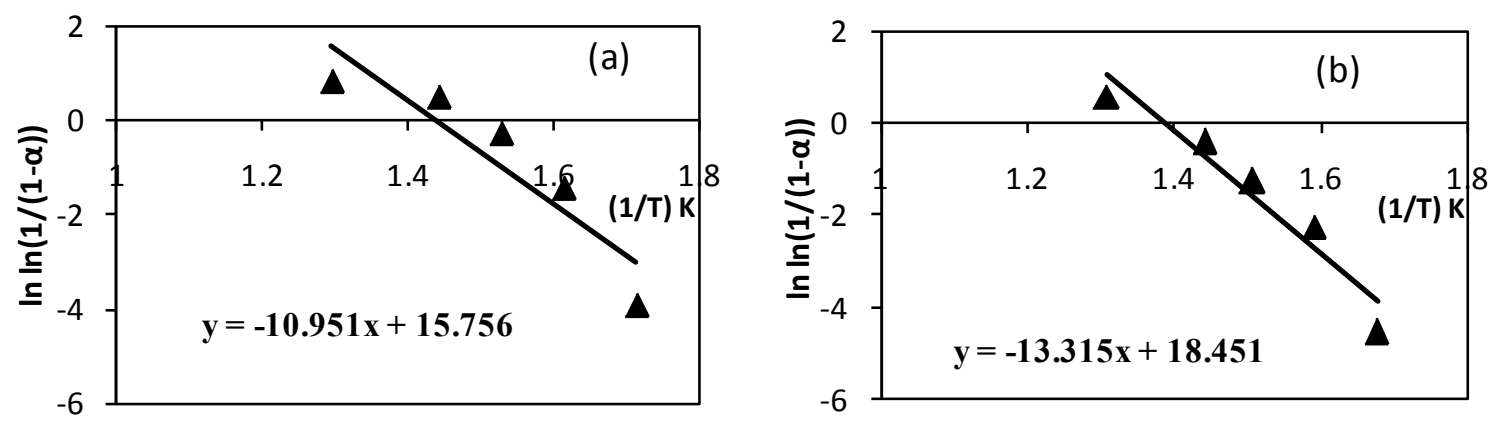

Figure 7. Kinetics expressions under (a) Air (b) Nitrogen at mosphere

\subsection{Pyrolysis Yield}

In the case of burning, the copper particles were covered with oxides. While the samples were partly carbonised due to the pyrolysis, and they differed from the samples exposed to the burning due to its dark colour. The copper particles during pyrolysis remained unreacted. Figure. 8 represents the difference between these samples.

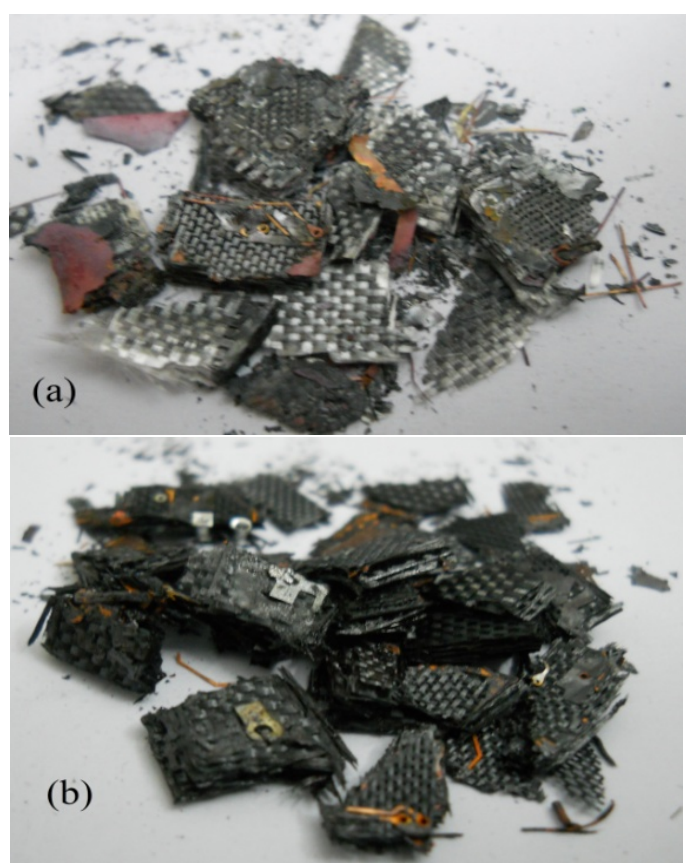

Figure 8. Photographs of PCBs scrap (a)Burned (b)Pyrolysed at $600^{\circ} \mathrm{C}$ for $50 \mathrm{mins}$

Other than solid, liquid and gas yields were obtained in the pyrolysis experiments carried out under nitrogen atmosphere. While in case of combustion, as the organic matter was oxid ised no separate liquid yield was obtained. The liquid fraction obtained during pyrolysis consisted of brown colour low viscous oil, while the gases which were passed through the acid solution changed its colour from transparent to reddish brown.

\subsection{Recovery of Copper by Leaching}

The comparison of copper recovery obtained from untreated, pyrolysed and air-burned samples by nitric acid leaching is presented (Figure. 9).

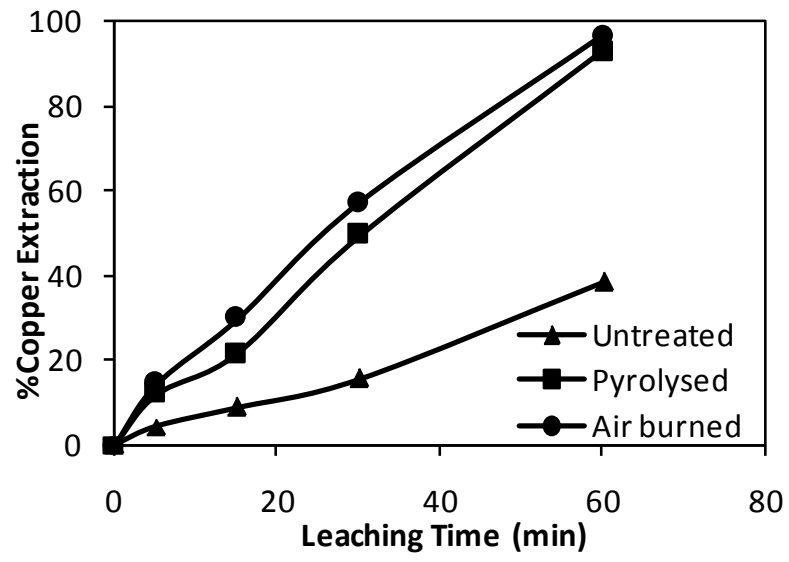

Figure 9. Effect of thermal pre-treatment on metal recovery by leaching with time

The maximum amount of copper extracted after one hour of leaching from untreated sample was $38.4 \%$ indicating metal recovery in the case of directly leached sample was low and the process was very inefficient. The metallic copper layers are overlaid by the laminate layers in the PCBs. This construction causes problems in the processing because the la minate inhibits the contact between a reaction medium and copper, which makes copper recovery difficult.

However, thermal pre-treatment significantly improved the copper recovery, as in both the cases (combustion and pyrolysis) a considerable amount of organic matter was removed, thereby liberating the copper which was earlier trapped inside the laminate. Metal recovery for pyrolysis and combustion were found to be $92.5 \%$ and $96.2 \%$, respectively.

\section{Conclusions}

The characteristics of low temperature pyrolysis of printed circuit boards subjected to air and nitrogen atmosphere was studied. The impact of the thermal pre-treatment on the subsequent hydrometallurgical recovery of copper from $\mathrm{PCB}$ by leaching was also examined. On the basis of the present study following conclusions can be drawn:

1) The thermal treat ment at the temperature of $300^{\circ} \mathrm{C}$ does not have any marked influence on the release of plastics from PCBs. With increase in temperatures the amount of plastics 
removed increases. Temperature of about $500{ }^{\circ} \mathrm{C}$ and duration about 50 minutes are sufficient for the effective removal of vo latile co mpounds of PCB.

2) The pyrolysis behaviour can be divided into three stages. The first stage is up to temperature of $296^{\circ} \mathrm{C}$ where no loss in the weight of the PCB scrap was observed. The next stage was between $296-500{ }^{\circ} \mathrm{C}$ where rapid decomposition of the PCB scrap took place. While the third stage was observed above $500{ }^{\circ} \mathrm{C}$ where the rate of decomposition became almost constant.

3) The weight loss achieved under similar conditions by combustion was slightly higher than that of pyrolysis. Also the activation energy calculated indicated that combustion was more favourable than pyrolysis; however the difference was not large.

4) Copper recovery from the untreated sample was poor. However copper recovery obtained from combustion and pyrolysis were considerably higher indicating prior thermal treatment is necessary along with mechanical upgradation in order to improve the process efficiency, thus making pyrolysis as an economical alternative for recycling PCBs.

\section{REFERENCES}

[1] P. Gramatyka, R. Nowosielski, P. Sakiewicz, "Recy cling of waste electrical and electronic equipment, Journal of Achievements in Materials and Manufacturing Engineering", vol.20, pp.535-538, 2007.

[2] Jirang Cui, Lifeng Zhang, "Metallurgical recovery of metals from electronic waste: A review", Journal of Hazardous Materials, vol.158, pp.228-256, 2008.

[3] H. Veldbuizen, B. Sippel, "Mining discarded electronics", Ind. Environ, vol.17, no.3, pp.7, 1994.

[4] F. Veglio, R. Quaresimaa, P. Fornarib, S. Ubaldinib, "Recovery of valuable metals from electronic and galvanic industrial wastes by leaching and electrowinning", Waste Management, vol.23, pp.245-252, 2003.

[5] P. Quinet, J. Proost, A. Van Lierde, "Recovery of precious metals from electronic scrap by hydrometallurgical processing routes", Minerals \& Metallurgical Processing, Vol.22, no.1, pp.17-22, 2005.

[6] T. Havlik, D. Orac, M. Petranikova, A. Miskufova, "Hydrometallurgical treatment of used printed circuit boards after thermal treatment", Waste Management, vol.31, no.7, pp.1542-1546, 2011.

[7] H.M. Veit, T.R. Diehl, A.P. Salami, J.S. Rodrigues, A.M Bernardes, J.A.S. Tenório, "Utilization of magnetic and electrostatic separation in the recycling of printed circuit boards scrap", Waste Management, vol.25, pp. 67-74, 2005.

[8] N.Mohabuth,P. Hall, N. Miles, "Investigating the use of vertical vibration to recover metal from electrical and electronic waste", Minerals Engineering, vol.20, pp.926-932, 2007.
[9] C. Duana, X. Wenb, C. Shic, Y.Zhaoa, B.Wena, Y Hea, "Recovery of metals from waste printed circuit boards by a mechanical method using a water medium", Journal of Hazardous Materials, vol.166, pp.478-482, 2009.

[10] Cui Quan, Aimin Li, Ningbo Gao, Synthesis of carbon nanotubes and porous carbons from printed circuit board waste py roly sis oil, Journal of Hazardous Materials, vol.179, pp.911-917, 2010.

[11] S. Pimenta, S.T. Pinho, "Recycling carbon fibre reinforced polymers for structural applications: Technology review and market outlook". Waste Management, vol.31, pp.378-392, 2011.

[12] Tzong-HorngLiou, "Pyrolysis kinetics of electronic packaging material in a nitrogen atmosphere", Journal of Hazardous Materials, vol.103, no.1-2, pp.107-12, 2003.

[13] Jinhui Li , HuaboDuan, Keli Yu, Lili Liu, Siting Wang, "Characteristic of low-temp erature py roly sis of printed circuit boards subjected to various atmosphere", Resources, Conservation and Recycling, vol.54,no.11, pp.810-815, 2010.

[14] Laishou Longa, ShuiyuSuna, Sheng Zhonga, WencanDaia, Jingy ong Liua, WeifengSonga, "Using vacuum pyrolysis and mechanical processing for recycling waste printed circuit boards", Journal of Hazardous Materials, vol.177, no.1-3, pp.626-632, 2010

[15] QingiieGuo, XuehaiYue, Minghua Wang, Yongzhuo Liu, "Py rolysis of scrap printed circuit board plastic particles in a fluidized bed", Powder Technology, vol.198, pp.422-428, 2010 .

[16] W.J. Hall, P.T. Williams, "Analysis of products from the pyrolysis of plastics recovered from the commercial scale recycling of waste electrical and electronic equipment", Journal of Analytical and Applied Pyrolysis, vol.79, pp. 375-386, 2007.

[17] G.Jie, L.Y. Shun, L.M. Xi, "Product characterization of waste printed circuit board by pyroly sis", Journal of Analytical and Applied Pyrolysis, vol.83, no.2, pp.185-189, 2008.

[18] Cui Quan, Aimin Li, Ningbo Gao, Zhang dan, "Characterization of products recycling from PCB waste pyrolysis", Journal of Analytical and Applied Pyrolysis, vol.89, no.1, pp.102-106, 2010.

[19] Chiang H, Lin K, Lai M, Chen T, Ma S. "Pyrolysis characteristics of integrated circuit boards at various particle sizes and temperatures", Journal of Hazardous Materials, vol.149, no.1, pp.151-159, 2007.

[20] J. Molto, R. Font, A.Ga'lvez, JA Conesa,"Pyrolysis and combustion of electronic wastes", Journal of Analytical and Applied Pyrolysis, vol.84, pp.68-78, 2009.

[21] Cui Quan, Aimin Li, Ningbo Gao, "Thermogravimetric analy sis and kinetic study on large particles of printed circuit board wastes", Waste Management, Vol.29, no.8, pp. 2353-2360, 2009.

[22] PiyaratWeerachanchai, ChaiyotTangsathitkulchai, Malee Tangsathitkulchai, "Comparison of pyroly sis kinetic models for thermogravimetric analysis of biomass", Suranaree Journal of Science and Technology, vol.17, no.4, pp. 387-400, 2010 . 